\title{
Atributos morfométricos e hidrológicos da Bacia Hidrográfica do Alto Sapucaí, Minas Gerais
}

\section{Morphometric and hydrological characterization of High Sapucaí Hydrographic Basin, Minas Gerais}

\author{
Lucas Emanuel Servidoni ${ }^{* 1} \bowtie\left(\mathbb{D}\right.$, Joaquim Ernesto Bernardes Ayer ${ }^{2} \bowtie(\mathbb{D}$, Paulo Vitor Moraes

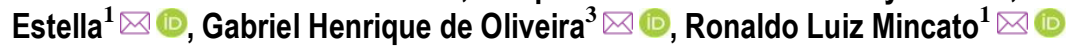

\author{
1Programa de Pós-graduação em Ciências Ambientais, Universidade Federal de Alfenas, \\ Alfenas, Minas Gerais, Brasil \\ ${ }^{2}$ Centro Universitário de Paulínia - UNIFACP, Paulínia, São Paulo, Brasil \\ 3Programa de Pós-graduação em Geografia, Universidade Federal de Alfenas, Alfenas, Minas \\ Gerais, Brasil \\ E-mail: joaquimeba@gmail.com (JEBA); paulo_v01@yahoo.com.br (PVME); \\ gaoliveira123@gmail.com (GHO); ronaldo.mincato@unifal-mg.edu.br (RLM) \\ *E-mail para correspondência: les.servidoni@gmail.com (LES)
}

Recebido (Received): 18/05/2020 Aceito (Accepted): 18/08/2020

\begin{abstract}
Resumo: A caracterização morfométrica de bacias hidrográficas é fundamental para análises hidrológicas e ambientais. Pois, pode contribuir com políticas de planejamento e gerenciamento de recursos naturais e de prevenção à enchentes e inundações. Neste cenário, o trabalho analisou as características morfométricas e hidrológicas da Bacia Hidrográfica do Alto Sapucaí, sul do Estado de Minas Gerais, para fornecer subsídios técnicos para o adequado gerenciamento dos seus recursos hídricos. Para tanto, foram calculados os parâmetros: densidade de rios, densidade de drenagem, relação de relevo, índice de rugosidade, coeficiente de compacidade, fator de forma e coeficiente de manutenção. Os dados referentes à vazão foram obtidos de uma estação de monitoramento fluvial da Agência Nacional de Águas e organizados pelo Sistema Computacional para Análise Hidrológica e pelo aplicativo Excel para obtenção, no período de 1994 a 2013, da vazão média anual, vazão média de longo prazo, vazão máxima de longo prazo, vazão mínima de longo prazo e os desvios em relação à média. Os dados de precipitação foram obtidos pelo Climate Hazards Group Infrared Precipitation with Stations e reunidos em precipitação média mensal e precipitação média anual para o período. Os dados permitiram caracterizar a Bacia Hidrográfica do Alto Sapucaí como propensa a enchentes, devido aos valores de densidade de drenagem maiores que 15,01, de densidade de rios maiores do que 3,01 e coeficiente de compacidade de 0,89. Tais valores indicam a necessidade de estratégias de prevenção à enchentes e inundações, como o reestabelecimento de áreas verdes e evitar a ocupação antrópica nessas áreas.
\end{abstract}

Palavras-chave: Hidrologia orbital; Fluviometria; Pluviometria; Recursos Hídricos.

Abstract: The morphometric characterization of hydrographic basins is essential for hydrological and environmental analysis. It allows can contribute to policies for planning and managing natural resources and preventing floods. This work analyzed the morphometric and hydrological characteristics of the High Sapucai River basin, south of Minas Gerais State, to provide technical support for the proper management of its water resources. For this purpose, the parameters river density, drainage density, relief ratio, roughness index, compactness coefficient, form factor and maintenance coefficient were calculated. The flow data were obtained by the fluvial monitoring station of the National Water Agency and organized by the Computational System for Hydrological Analysis and the Excel application to obtain, from 1994 to 2013, the average annual flow, long-term average flow, maximum long-term flow, flow long-term minimum and deviations the average. Precipitation data were obtained by the Climate Hazards Group Infrared Precipitation with Stations and gathered in average monthly precipitation and average annual precipitation for the period. The dataset allowed to characterize the Alto Sapucai Hydrographic Basin as prone to flooding, due to the values of drainage density greater than 15.01, river density greater than 3.01 and compactness coefficient of 0.89. 
These values indicate the need for flood prevention strategies, such as the reestablishment of green areas and avoiding anthropic occupation in these areas.

Keywords: Orbital Hydrology; Fluviometry; Rainfall; Water Resources.

\section{Introdução}

A análise e a caracterização morfométrica e hidrológica de bacias hidrográficas permitem abordar questões relacionadas ao ambiente fluvial e podem contribuir com a gestão eficaz para prevenção de riscos às enchentes e inundações. Para tanto, esse tipo de trabalho é indispensável para produção de informações sobre o comportamento fluvial e pluviométrico de bacias hidrográficas (WU et al. 2019). E, depois, contribuir com conhecimentos para o desenvolvimento e execução de planos de manejo compatíveis com a realidade local e com a Política Nacional de Gerenciamento de Recursos Hídricos (BRASIL, 1997).

A disponibilidade e a demanda por recursos hídricos são responsáveis por disputas em regiões de escassez de água. Assim, compreender os aspectos do comportamento hidrológico permite identificar a melhor solução para os problemas associados aos diferentes usos da água (WU et al. 2019). Para tanto, é necessário compreender as interações que afetam o ciclo das águas pluviais e alteram as dinâmicas de escoamento superficial, de infiltração e da evapotranspiração na superfície terrestre, em escala de bacias hidrográficas e de vertentes. O comportamento destas variáveis decorre da estrutura geológica, geomorfológica, pedológica e climática das bacias hidrográficas (NAGARAJU et al. 2017).

Bacias hidrográficas são áreas banhadas por um rio principal e seus afluentes que fluem para o exutório. Além disso, é composta por solos, rochas e formas de relevo que atuam em conjunto e definem a sua dinâmica hidrológica. As atividades humanas, tais como, sistemas agrícolas, indústrias e áreas urbanas podem ocorrer no interior das bacias e influenciar a entrada e saída de materiais e energia. Portanto, a bacia hidrográfica é a unidade básica de estudos geocientíficos, pois todos os fenômenos naturais ou antrópicos têm causa e efeito no seu interior (ULIBARRI; GARCIA, 2020).

A análise morfométrica de bacias hidrográficas consiste em avaliar e descrever as características da rede de drenagem, do relevo e suas relações (NAGARAJU et al. 2017). Tais aspectos junto com as características climáticas regionais influenciam a quantidade e o comportamento das águas produzidas no deflúvio, na ocorrência e distribuição das precipitações, no escoamento superficial e subsuperficial, na evapotranspiração e na qualidade e propriedades físicas e químicas das águas (ALMEIDA et al. 2017).

Os atributos fisiográficos de bacias hidrográficas afetam diretamente os processos hidrológicos, climáticos e as atividades humanas, como o agronegócio, o abastecimento público, a indústria e a produção de energia hidrelétrica. Portanto, o seu conhecimento é essencial para diagnosticar as alterações, com e sem interferências antrópicas, e traçar planos de controle, adaptação e monitoramento para os novos cenários desencadeados pelas mudanças climáticas locais e globais (TAOFIK et al. 2017).

Os parâmetros morfométricos do relevo, da rede hidrográfica e pluviométricos são fundamentais para determinar as características hidrológicas de uma bacia hidrográfica. Medhi et al., (2017) demonstraram que é possível a partir desses atributos identificar a possibilidade de uma bacia hidrográfica sofrer processos hidrometeorológicos extremos, como enchentes e inundações. Tais autores apontaram também que os parâmetros utilizados na análise podem ainda serem indicativos do potencial de exploração de águas subterrâneas. Portanto, a análise morfométrica é uma alternativa viável e de baixo custo para contribuir com o planejamento público e privado de empreendimentos agrícolas, industriais, imobiliários e para prevenção e mitigação de enchentes e inundações.

As técnicas de geoprocessamento e de sensoriamento remoto são eficazes para determinação dos parâmetros morfométricos e permitem calcular atributos como a densidade de drenagem, o índice de bifurcação e a relação de relevo de bacias hidrográficas de forma automatizada e com custos reduzidos, colaborando para apontar áreas prioritárias e urgentes para investimentos na conservação dos recursos naturais e para elaboração de planos de manejo para as áreas com riscos à enchentes e inundações (TAOFIK et al. 2017). Quando combinados, os elementos de geoprocessamento e de sistema de informação geográfica (SIG) possibilitam avaliar e monitorar, tanto quantitativa, como qualitativamente, fenômenos e eventos ambientais e, assim, contribuir com informações para sustentar e amparar as tomadas de decisões por órgãos públicos e privados (TAOFIK et al. 2017).

A Bacia Hidrográfica do Alto Sapucaí possui histórico de enchentes e inundações recorrentes nas cidades de Itajubá, Santa Rita do Sapucaí Delfin Moreira, Piranguinho e Piranguçu (DEFESA CIVIL, 2020). Assim, foram descritas, calculadas e avaliadas as características morfométricas do relevo e da rede de drenagem para auxiliar a gestão de áreas de risco. Visou ainda analisar o comportamento hidrometeorológico a partir das 
vazões e precipitações de 1994 a 2013, da rede de monitoramento da Agência Nacional de Águas (ANA) e de sensores orbitais. O período de tempo foi selecionado com base nos dados disponíveis nas agências reguladoras. Vale salientar que neste período a área foi recorrentemente vitima de enchentes e inundações com sérios prejuízos socioeconômicos e ambientais.

\section{Materiais e métodos}

\section{1 Área de estudo}

A Bacia Hidrográfica do Alto Sapucaí é afluente da Bacia do Rio Grande, localizada na Região Sudeste do Brasil, nos Estados de Minas Gerais e São Paulo (Figura 1). A área de drenagem do Alto Sapucaí é de $2.813 \mathrm{~km}^{2}$ e a vazão média é de $146 \mathrm{~m}^{-3} \mathrm{~s}^{-1}$. O Alto Sapucaí é estratégico para a região do sul de Minas Gerais, pois as águas são usadas no abastecimento público e industrial, irrigação e abastecimento do reservatório da Usina Hidrelétrica de Furnas (VIANNA; AVELAR, 2010).
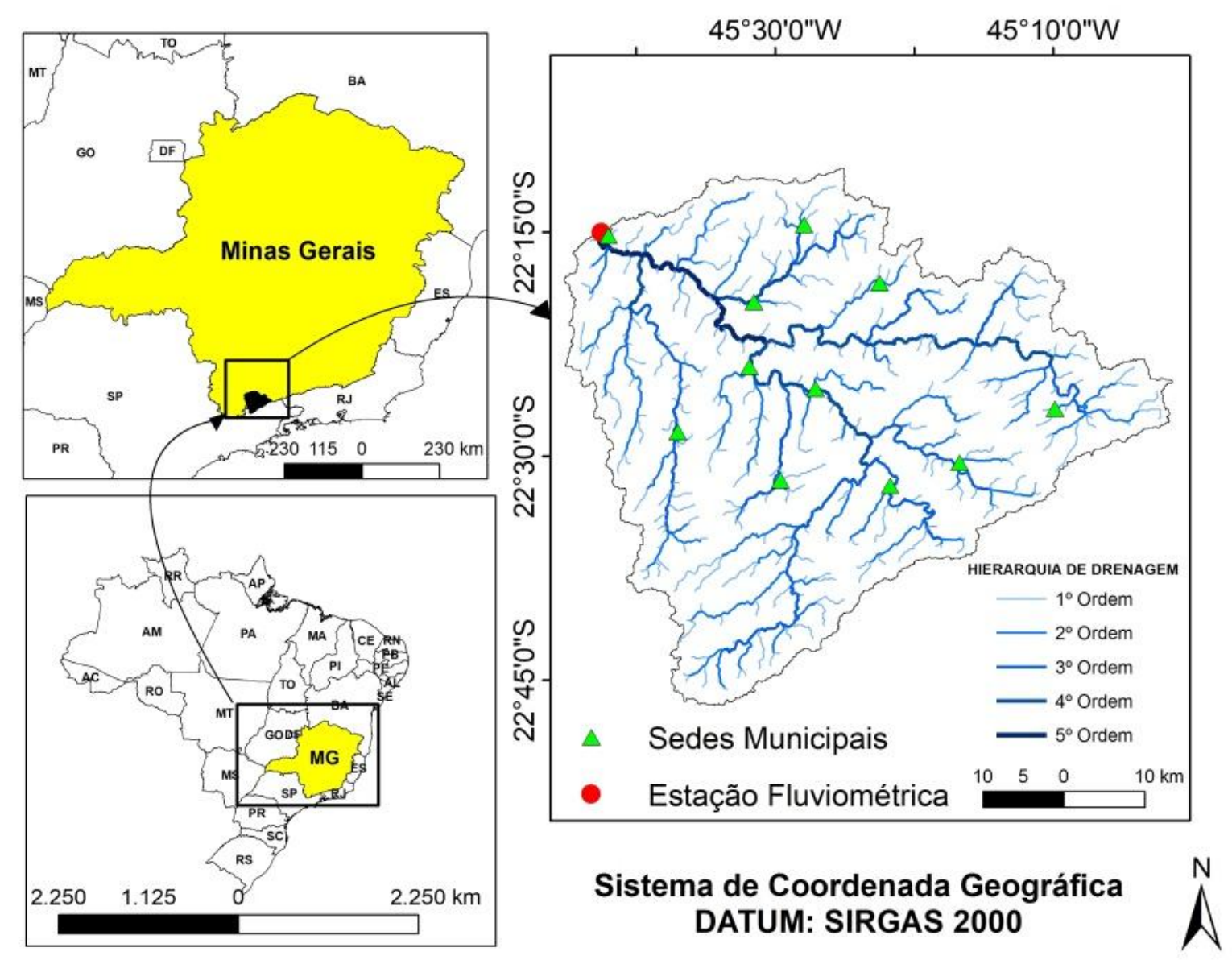

Figura 1: Mapa de Localização da Bacia Hidrográfica do Alto Sapucaí, MG.

O arcabouço geológico da área é formado principalmente por complexos granito-gnáissicos do Sistema Orogênico do Tocantins (CPRM, 1998). Tais complexos são, em geral, impermeáveis e aliados ao relevo íngreme potencializam a ação das águas fluviais e pluviais em eventos chuvosos. A geomorfologia é caracterizada pelo Domínio das Unidades Denudacionais em Rochas Cristalinas ou Sedimentares, com altimetria entre 816 e 1.482 m (RIBEIRO et al. 2016). A bacia hidrográfica do Alto Sapucaí está associada à Serra da Mantiqueira. Devido à isso, há vales profundos com divisores marcados pela presença de escarpas abruptas, além de vales altimontanos com planícies aluviais soerguidas. A jusante é composta por declives e vertentes suaves (SGARBI; DARDENNE, 2002). Na hidrografia, o padrão de drenagem dominante é o dendrítico, com canais de $1^{\mathrm{a}}$ a $5^{\mathrm{a}}$ com direção preferencial NE-SO (RIBEIRO et al. 2016).

O clima, de acordo com a classificação de Köppen é tropical de altitude (Cwa e Cwe), com verão quente e úmido e inverno frio e seco e precipitação média anual de 1.600 a 1.865 mm (MELLO et al. 2007; SPAROVEK et al. 2007; AQUINO et al. 2012). O Domínio Morfoclimático é a Mata Atlântica, com 
Floresta Estacional Semidecídua, substituída em sua maior parte por pastagens, cultivos agrícolas e silvicultura (SCOLFORO et al. 2008).

\subsection{Análise morfométrica}

Os parâmetros morfométricos da Bacia Hidrográfica do Alto Sapucaí foram calculados a partir do modelo digital de elevação (MDE) Shuttle Radar Topography Mission 2 (SRTM 2) com resolução vertical de 30 m, que atende aos critérios de escala do estudo, conforme Gupta et al., (2017). O MDE foi processado em SIG pelo módulo Hydrology do conjunto Spatial Analisty Tools e ArcHydro para obtenção da base cartográfica, que consiste nos mapas de Declividade, de Altimetria e de Hidrografia. Para remoção dos pixels com valores de altimetria nulos foi utilizada a extensão Fill do ArcGIS 10.5 (ESRI, 2015), para redução das falhas e erros nos cálculos dos parâmetros morfométricos. Para extração automática da rede de drenagem foi usada a extensão Hidrology do ArcGIS 10.5, a partir dos processos fill, flow direction, flow accumulation, con, stream to featur e wathershed (ESRI, 2015). Os parâmetros utilizados, junto às equações e variáveis, com os seus significados e as referências consideradas estão listados na Tabela 1.

Tabela 1: Parâmetros Morfométricos da Bacia Hidrográfica do Alto Sapucaí, MG.

\begin{tabular}{|c|c|c|c|c|}
\hline Parâmetro & Equação & Variáveis & Significado & Referências \\
\hline $\begin{array}{l}\text { Densidade de } \\
\text { Rios (Dh) }\end{array}$ & $D h=\frac{n}{A}$ & $\begin{array}{l}\mathrm{n}=\text { número de } \\
\text { canais } \\
\mathrm{A}=\text { área }\end{array}$ & $\begin{array}{l}\text { Expressa o número de canais existentes } \\
\text { por unidade de área. Indica o potencial } \\
\text { hídrico da região }\end{array}$ & $\begin{array}{l}\text { Strahler } \\
(1952)\end{array}$ \\
\hline $\begin{array}{l}\text { Densidade de } \\
\text { drenagem } \\
\text { (Dd) }\end{array}$ & $D d=\frac{C}{A}$ & $\begin{array}{l}\mathrm{C}=\text { comprimento } \\
\text { total dos canais } \\
\mathrm{A}=\text { área }\end{array}$ & $\begin{array}{l}\text { Expressa a influência do fornecimento e } \\
\text { transporte de material dendrítico ou indica } \\
\text { o grau de antropização dos canais }\end{array}$ & $\begin{array}{l}\text { Horton } \\
(1945)\end{array}$ \\
\hline $\begin{array}{l}\text { Relação de } \\
\text { relevo (Rr) }\end{array}$ & $R r=\frac{\Delta a}{L}$ & $\begin{array}{l}\Delta \mathrm{a}=\text { amplitude } \\
\text { altimétrica } \\
\mathrm{L}=\text { comprimento } \\
\text { do canal }\end{array}$ & $\begin{array}{l}\text { Relação entre a amplitude altimétrica com } \\
\text { o comprimento do canal principal }\end{array}$ & $\begin{array}{l}\text { Strahler } \\
(1952)\end{array}$ \\
\hline $\begin{array}{l}\text { Índice de } \\
\text { rugosidade } \\
\text { (Ir) }\end{array}$ & $\begin{array}{l}\operatorname{Ir}=\operatorname{Hm} x \\
\operatorname{Dd}\end{array}$ & $\begin{array}{l}\text { Hm = amplitude } \\
\text { altimétrica } \\
\text { Dd = Densidade } \\
\text { de drenagem }\end{array}$ & $\begin{array}{l}\text { Representa a relação declividade com os } \\
\text { comprimentos de canais. Indica o grau de } \\
\text { dissecação da bacia hidrográfica }\end{array}$ & $\begin{array}{l}\text { Horton } \\
(1945)\end{array}$ \\
\hline $\begin{array}{l}\text { Coeficiente } \\
\text { de } \\
\text { Compacidade } \\
(\mathrm{Kc})\end{array}$ & $\begin{array}{l}K c=0,28 \\
\frac{P}{\sqrt{A}}\end{array}$ & $\begin{array}{l}\mathrm{P}=\text { Perímetro da } \\
\text { bacia em } \mathrm{km} \\
\mathrm{A}=\text { Área da } \\
\text { Bacia em } \mathrm{km}^{2}\end{array}$ & $\begin{array}{l}\text { Indica a maior ou menor probabilidade de } \\
\text { ocorrência de cheias }\end{array}$ & $\begin{array}{l}\text { Horton } \\
(1945)\end{array}$ \\
\hline $\begin{array}{l}\text { Fator de } \\
\text { Forma (Kf) }\end{array}$ & $K f=\frac{A}{L^{2}}$ & $\begin{array}{l}\mathrm{A}=\text { Área da bacia } \\
\text { em } \mathrm{km}^{2} \\
\mathrm{~L}=\text { comprimento } \\
\text { axial da bacia }\end{array}$ & $\begin{array}{l}\text { Valores baixos indicam bacia menos } \\
\text { sujeita a enchentes }\end{array}$ & $\begin{array}{l}\text { Strahler } \\
(1952)\end{array}$ \\
\hline $\begin{array}{l}\text { Coeficiente e } \\
\text { Manutenção } \\
(\mathrm{Cm})\end{array}$ & $C m=\frac{1}{D d}$ & $\begin{array}{l}\text { Dd = Densidade } \\
\text { de Drenagem }\end{array}$ & $\begin{array}{l}\text { Indica a área mínima necessária para } \\
\text { manter perene canais de drenagem }\end{array}$ & $\begin{array}{l}\text { Schumm } \\
(1956)\end{array}$ \\
\hline $\begin{array}{l}\text { Extensão do } \\
\text { Percurso } \\
\text { Superficial } \\
\text { (Eps) }\end{array}$ & Eps $=\frac{1}{2 \cdot D d}$ & $\begin{array}{l}\text { Dd }=\text { Densidade } \\
\text { de Drenagem }\end{array}$ & $\begin{array}{l}\text { Indica a extensão média percorrida pelo } \\
\text { escoamento até o canal de drenagem }\end{array}$ & $\begin{array}{l}\text { Christofoletti } \\
(1969)\end{array}$ \\
\hline
\end{tabular}

O flow direction avalia a capacidade natural da água de escoar pelo caminho mais fácil. Dessa forma, o algoritmo avalia o MDE, pixel a pixel, identificando os fundos de vales e de talvegues. Pelo flow direction, as áreas mais prováveis para o escoamento da água são mapeadas e examinadas na ferramenta flow accumulation que identifica os locais prováveis de acúmulo de água. Em seguida, com a extensão stream to 
features foram unidas as áreas de acumulação e de escoamento d'água, delimitando os canais de drenagem (ESRI, 2015).

O módulo de análise ArcHydro possibilitou delimitar 170 sub-bacias hidrográficas na área e definir a hierarquia de drenagens, conforme Strahler (1957). A delimitação das sub-bacias hidrográficas atendeu os critérios de altimetria, de declividade do relevo e de áreas de fluxo e acumulação, que identificam com precisão os divisores de águas da bacia (GUPTA et al. 2017). A escala de representação da bacia seguiu a determinação da hierarquia de drenagens, sendo um rio de quinta ordem. De acordo com a ordem, foram mapeadas, 102 bacias de primeira, 55 de segunda, 9 de terceira, 3 de quarta e 1 de quinta. Os parâmetros morfométricos foram calculados para as 170 sub-bacias delimitadas de forma individual pelo ArcHydro, conforme Gupta et al., (2017). O cálculo dos parâmetros morfométricos foram feitos com a ferramenta Field Calculator do ArcGIS 10.5 (ESRI, 2015).

Para avaliação de pontos de ruptura ou knickpoints, no perfil longitudinal do canal principal, foi confeccionado o perfil topográfico do Alto Sapucaí utilizando a ferramenta 3D Analyst do ArcGIS 10.5 conforme Gailleton et al., (2019). Em seguida, os pontos de ruptura foram associados aos índices morfométricos e hidrológicos.

\subsection{Dados hidrológicos}

A análise das vazões foi baseada nos dados da estação de monitoramento fluvial 61410000 da ANA, disponível na plataforma HidroWeb (www.snirh.gov.br/hidroweb). Foi selecionada a estação fluvial que atendeu ao critério de poucas lacunas da série de dados temporais. Assim, foi optado pela estação com lacunas menores do que 5\% e alcance temporal de 20 anos (1994 - 2013). A série considerou 20 anos, devido às limitações históricas de dados disponíveis a partir da estação de monitoramento fluvial representativa da área. Após, os dados foram organizados e tratados nos softwares Sistema Computacional para Análise Hidrológica (SisCAH) e Excel para a obtenção da vazão média de longo prazo, da vazão máxima de longo prazo, da vazão mínima de longo prazo e do desvio da vazão em relação à média.

A análise das precipitações foi baseada nos dados do Climate Hazards Group Infrared Precipitation with Stations (CHIRPS), disponíveis na Universidade da Califórnia (www.chc.ucsb.edu/data/chirps). Os dados de 20 anos (1994 - 2013) foram organizados no software Excel, para ilustrar a precipitação média anual, a precipitação mínima e máxima anual e o climograma da área. No ArcGIS 10.5 foi elaborado o mapa da distribuição espaço-temporal da precipitação média mensal entre 1994 e 2013, de acordo com Costa et al., (2019).

Os dados disponibilizados pelo CHIRPS (COSTA et al. 2019) são organizados em arquivo matricial em que cada célula da matriz possui $5 \mathrm{~km}^{2}$. Os pixels da imagem foram reamostrados para representar os dados de precipitação em células de $1 \mathrm{~km}^{2}$. Na sequência, foi aplicada técnica de suavização bilinear (COSTA et al. 2019) para melhorar a visualização das informações. A utilização de dados regionalizados de precipitação permite identificar as áreas com maior descarga de água e inferir locais onde a contribuição de águas pluviais é mais representativa na transferência precipitação-vazão.

No final, os resultados foram submetidos à avaliação e discussões comparativas com dados da literatura especializada e foram apresentadas e sugeridas medidas para contribuir com o planejamento e a gestão dos recursos hídricos e das áreas de risco a enchentes e inundações.

\section{Resultados e discussão}

A hierarquia de drenagem do Alto Sapucaí e as unidades amostrais são ilustradas na Figura 2A. A Bacia Hidrográfica do Alto Sapucaí, das nascentes na Serra da Mantiqueira, ao exutório na cidade de Santa Rita do Sapucaí, onde está a estação de monitoramento fluvial 61410000 , foi classificada como de $5^{\circ}$ Ordem, conforme Ribeiro et al., (2016).

A regionalização da densidade de drenagem (Dd) é apresentada na Figura 2B. A legenda do mapa foi organizada em quatro classes de acordo com a densidade de drenagem: áreas com Dd entre 0,00 e 3,00, entre 3,01 e 5,00, entre 5,01 e 15,00 e acima de $15,00 \mathrm{~km} \mathrm{~km}^{-2}$.

Os maiores valores de Dd acompanham o curso principal do rio, visto ser o principal canal receptor de drenagens de ordens inferiores e, portanto, com tendência de apresentar valores de Dd maiores. 

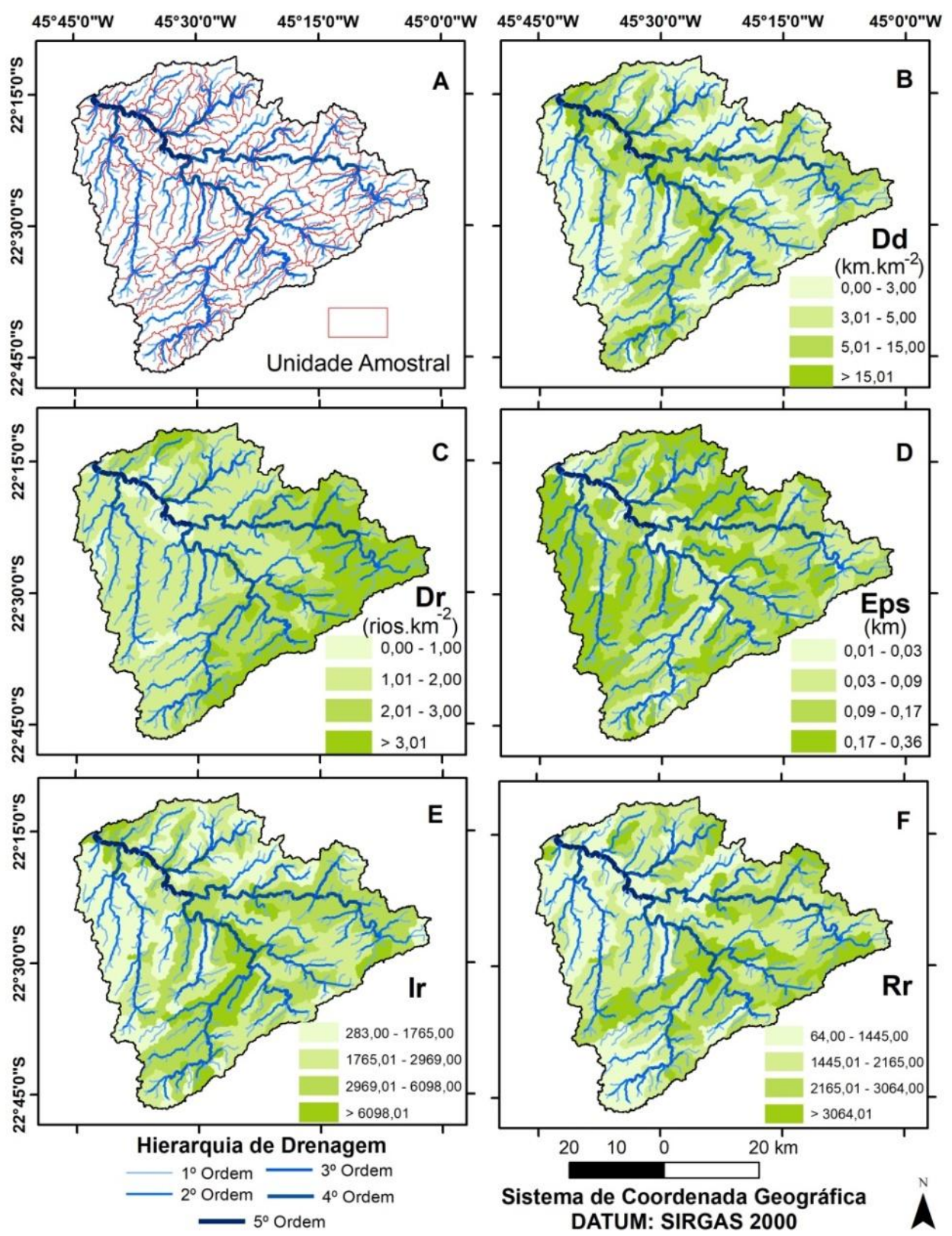

Figura 2: A) Mapa das Unidades Amostrais (sub-bacias); B) Mapa da Densidade de Drenagem; C) Densidade de Rios; D) Extensão do Percurso Superficial; E) Índice de Rugosidade; F) Relação de relevo; da Bacia Hidrográfica do Alto Sapucaí, MG.

Como indicativo da suscetibilidade à enchentes e inundações em bacias hidrográficas, a Dd média do Alto Sapucaí de $29 \mathrm{~km} . \mathrm{km}^{-2}$ ilustra tal comportamento, visto as recorrentes enchentes que ocorrem em Santa Rita do Sapucaí, Itajubá, Delfin Moreira, Piranguinho e Piranguçu, todas banhadas pelo rio principal. Os danos causados pelas enchentes e inundações ocorrem de dezembro a março. Os resultados ilustram que na região de Santa Rita do Sapucaí, os elevados valores de Dd associados aos eventos hidrometeorológicos extremos desencadeiam enchentes e inundações, conforme Servidoni et al., (2019). Dessa forma, é necessário a elaboração de um plano de contingência para a área, que aborde o comportamento hidrológico, climático, geomorfológico e do uso ocupação da bacia hidrográfica.

A Densidade de Rios (Dr) regionalizada é ilustrada na Figura 2C. A legenda está organizada em quatro classes: valores de Dr entre 0,00 e 1,00; 1,01 e 2,00; 2,01 e 3,00 e maior que 3,01 rios km$~^{-2}$. Com raras exceções a maior parte da área obteve valores entre 0,56 e 2,36 e 2,36 e 3,01 rios km ${ }^{-2}$ e cerca de $20 \%$ da área possuem valores acima de 3,01 rios. $\mathrm{km}^{-2}$. As áreas com valores entre 0,56 e 3,01 são áreas de solos permeáveis, onde predomina a infiltração, ou seja, o escoamento superficial é menor, que acarreta menor probabilidade de enchentes e inundações. Todavia, os $20 \%$ da área correspondente a valores acima de 3,01 são constituídas por rochas impermeáveis e bem drenadas, onde predomina o escoamento superficial associado a altas declividades aumentando a vazão e o poder destrutivo das águas em eventos de chuvas prolongadas ou curtas de alta intensidade (TAOFIK et al. 2017). 
As áreas com valores entre 2,36 e 3,01 e acima de 3,01 rios $\mathrm{km}^{-2}$ se sobrepõem em parte a Serra da Mantiqueira, o que explica os maiores valores de densidade de rios. Pois, regiões com elevadas declividades concentram maior quantidade de canais de primeira e segunda ordem (Figura 2C) (GUPTA et al. 2017).

A Extensão do Percurso Superficial (Eps) em km está na Figura 2D. Este parâmetro corresponde à distância média que um tributário percorre até o canal principal. Os maiores valores de Eps se concentram nos divisores de águas, que são áreas mais elevadas e com as maiores declividades. Dessa forma, a análise visual da Eps é coerente com o comportamento fisiográfico da bacia. O setor leste concentra os maiores valores de Eps. Essas áreas contribuem para descargas hídricas de maior energia, devido ao efeito gravitacional (ALMEIDA et al. 2013; KUNTAMALLA et al. 2018).

O índice de rugosidade (Ir), ilustrado na Figura 2E, aponta a relação entre a declividade e o comprimento dos canais. Assim, quanto maior o Ir mais declivoso e dissecado é o relevo, ou seja, mais entalhado é o formato dos canais de escoamento. Na área, os maiores valores de Ir se sobrepõem em parte ao canal principal na região à montante associada aos knickpoints. Os valores do Ir são coerentes e concordam com os resultados de Servidoni et al., (2019) para a Bacia Hidrográfica do Rio Machado, no sul de Minas Gerais, que também pertence à Bacia Hidrográfica do Rio Grande.

$\mathrm{Na}$ avaliação de parâmetros morfométricos de bacias hidrográficas, a partir de técnicas estatísticas, Purohit e Parmar (2017) constataram significativa relação direta entre os efeitos da inclinação do relevo e os aspectos morfométricos. Nos seus resultados foram notados que bacias hidrográficas localizadas sobre as encostas íngremes são altamente dissecadas e formadas por materiais mais granulosos, o que foi confirmado em expedições de campo, sustentando os resultados obtidos pela análise computacional na Bacia Hidrográfica do Alto Sapucaí.

A Relação de Relevo (Rr) regionalizada apresentada na Figura 2F é indicativa da declividade média da bacia. Os valores elevados da $\mathrm{Rr}$ indicam elevada declividade, o que é típico do relevo da Serra da Mantiqueira (RIBEIRO et al. 2016).

Todos os parâmetros morfométricos e variáveis necessárias para seu cálculo estão listados na Tabela 2. O Kc calculado foi de 0,89 e aponta elevados valores de vazão o que contribui para aumentar o poder destrutivo das águas pluviais e causar enchentes e inundações nas cidades de Itajubá, Santa Rita do Sapucaí, Delfin Moreira, Piranguçu e Piranguinho durante a estação chuvosa. O valor de Kc 0,89 foi obtido também por Taofik et al., (2017) numa bacia hidrográfica Tropical. A similaridade dos resultados obtidos para duas as áreas demonstra que ambas sofrem com enchentes e inundações. Tais valores comparados com outras referências demonstram que o $\mathrm{Kc}$ entre 0,75 e 1,00 caracterizam áreas propensas a alagamentos (STRAHLER, 1957; CHRISTOFOLETTI, 1969; SANGMAN \& BALAMURUGAN, 2017; SERVIDONI et al. 2019). O Kf obtido foi de 0,56 e indica que a bacia está sujeita a picos de enchentes e inundações, devido à forma circular de suas sub-bacias hidrográficas à jusante e aos dados de Kc. Tais áreas estão concentradas próximas a canais de elevada ordem, como o canal principal de quinta ordem e seus tributários de quarta ordem. Essa observação pode ser evidenciada pelo trabalho de Purohit e Parmar (2017), cujos resultados e observações coincidem com os dados obtidos na bacia hidrográfica do Alto Sapucaí. Assim, é necessário o planejamento e adoção de medidas para prevenir e mitigar a vulnerabilidade dessas áreas a processos hidrometeorológicos extremos (TAOFIK et al. 2017).

Tabela 2: Valores de Parâmetros Morfométricos da Bacia Hidrográfica do Alto Sapucaí, MG.

\begin{tabular}{ll}
\hline \multicolumn{1}{c}{ Parâmetro } & Valor \\
\hline Área da bacia & $2.813 \mathrm{~km}^{2}$ \\
Perímetro da bacia & $387 \mathrm{~km}$ \\
Altitude máxima & $2.329 \mathrm{~m}$ \\
Altitude mínima & $829 \mathrm{~m}$ \\
Altitude média & $1.586 \mathrm{~m}$ \\
Densidade de Drenagem (Dd) & $29 \mathrm{~km} \mathrm{~km}^{-2}$ \\
Densidade de Rios (Dr) & $2,49 \mathrm{canais} \mathrm{km}^{-2}$ \\
Quantidade de Rios & 175 \\
Soma de rios & $4.158 \mathrm{~km}$ \\
Coeficiente de Compacidade (Kc) & 0,89 adimensional \\
Fator de Forma (Kf) & 0,56 adimensional \\
Coeficiente de Manutenção (Cm) & $217 \mathrm{~m}^{2}$ \\
Relação de Relevo (Rr) & 2.332 adimensional \\
Índice de Rugosidade (Ir) & 5.384 adimensional \\
Extensão do percurso superficial (Eps) & $0,10 \mathrm{~km}$ \\
\hline
\end{tabular}


O Coeficiente de Manutenção $(\mathrm{Cm})$ (Tabela 2) permite representar qual seria a área necessária para que um canal de drenagem seja classificado como perene. No caso, o valor obtido para $\mathrm{Cm}$ foi de 217. Ou seja, é necessário $217,00 \mathrm{~m}^{2}$ de um canal de drenagem para que este se mantenha perene ao longo do ano.

A análise de knickpoints permitiu identificar uma expressiva ruptura de relevo a montante da bacia hidrográfica do Alto Sapucaí conforme a Figura 3.

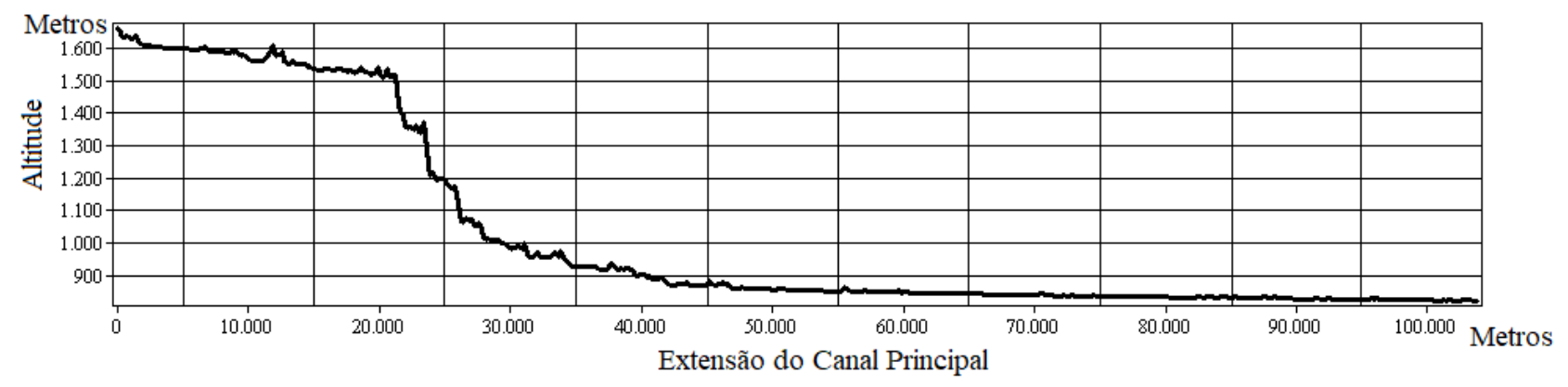

Figura 3: Perfil Longitudinal do canal principal da bacia hidrográfica do Alto Sapucaí.

A ruptura ilustrada na Figura 3 está inserida na área com Dd maior do que 15,01 e Dr maior do que 3,01, que classifica a área como bem drenada. Esta ruptura do relevo implica em um aumento potencial da vazão do curso principal podendo causar riscos às populações próximas a esta região ou a jusante do knickpoint mapeado (GAILLETON et al. 2019). Estas características das áreas à jusante são ilustradas por Ribeiro et al., (2016) no Município de Pouso Alegre.

Os dados das vazões médias anuais, da vazão média de longo prazo, das vazões máxima e mínima de longo prazo, de 1994 a 2013, estão representados na Figura 4A.
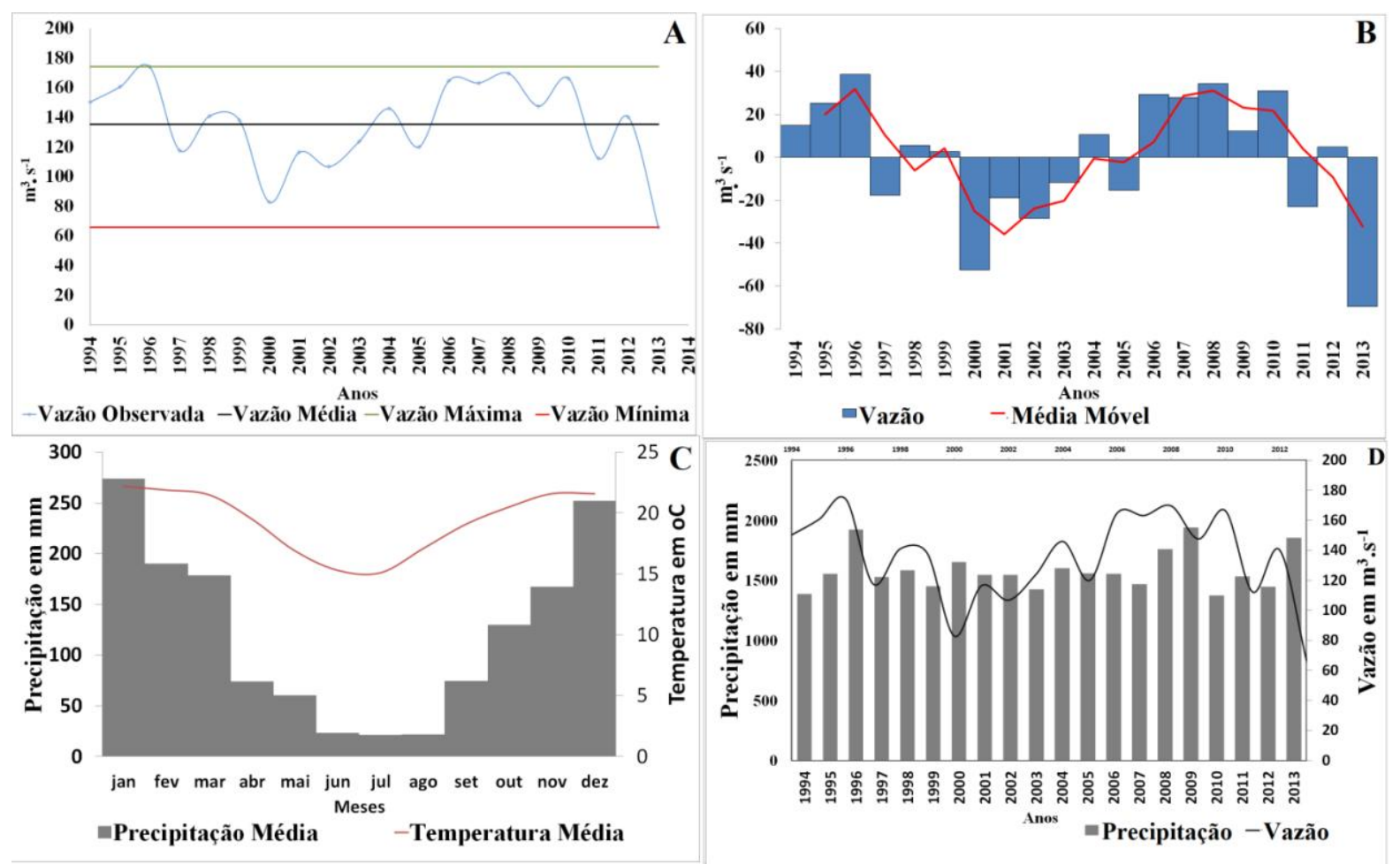

Figura 4: A) Vazão média anual, B) Desvios em relação à média anual das vazões, C) Climograma médio mensal da precipitação e da temperatura e D) Vazão Média Anual e Precipitação Média anual de 1994 a 2013 da Bacia Hidrográfica do Alto Sapucaí, MG.

A vazão média calculada no período foi de $135,39 \mathrm{~m}^{3} \mathrm{~s}^{-1}$. A vazão máxima de longo prazo atingiu 174,06 $\mathrm{m}^{3} \mathrm{~s}^{-1}$ entre 1995 e 1996. Em seguida, entre 1996 e 2000 ocorreu uma queda na vazão. Entre 2000 e 2007 houve um aumento progressivo da vazão e, novamente, entre 2007 e 2013 uma queda, quando foi apontada a menor vazão para o período estudado, de $65,98 \mathrm{~m}^{3} \mathrm{~s}^{-1}$. No período a vazão apresentou uma variação de $108,08 \mathrm{~m}^{3} \mathrm{~s}^{-1}$ (Figura 4A). 
A variação da vazão ocorre em função da sazonalidade do clima. Tal alternância influencia a conversão chuva-vazão o que pode elevar ou diminuir o nível dos cursos de água em períodos recorrentes nas respectivas estações chuvosas e secas. A resposta da conversão chuva-vazão na área é rápida, devido à ruptura do relevo ilustrada Figura 3. Tal informação possibilita aos gestores públicos direcionar investimentos em locais estratégicos, de forma a antecipar ações de prevenção de desastres naturais previamente aos eventos chuvosos.

A sazonalidade no regime climático típico de regiões tropicais é ilustrada pela Figura 4C, com duas estações bem definidas: o verão quente e úmido, que concentra a pluviosidade e o inferno frio e seco, com estiagem. Esta sazonalidade é, em geral, negligenciada pelos gestores públicos e promove a intranquilidade na população das áreas densamente povoadas, devido favorecer eventos de enchentes e inundações (YAN $e t$ al. 2019), como observado nas regiões metropolitanas de São Paulo e Belo Horizonte, no verão de 2020. As variações do clima aliadas à ausência de planejamento urbano são responsáveis pelas tragédias recorrentes que poderiam ser evitadas com planejamento urbano, investimentos em infraestrutura e capacitação técnica da Defesa Civil para fornecer respostas imediatas para situações emergenciais (CELARINO \& LADEIRA, 2014).

Os desvios em relação à média anual de vazões do Alto Sapucaí de 1994 a 2013 estão representadas na Figura 4B, e permitem identificar quatro cenários distintos: o primeiro entre 1994 e 1996 marcado por vazões acima da média de 135,39 $\mathrm{m}^{3} \cdot \mathrm{s}^{-1}$ (Figura 4B); o segundo de 1997 a 2006 com vazões abaixo da média, exceto em 1998, 1999 e 2004 com valores levemente acima da média (Figura 4B); o terceiro cenário, de 2007 a 2010, com desvios anuais da vazão positivos em relação à média; e, por fim, o quarto entre 2011 e 2013 com vazões anuais abaixo da média (Figura 4B). A média móvel ilustra o comportamento dos desvios anuais da vazão em relação à média e estão representados pela linha vermelha na Figura $\mathbf{4 B}$, ilustrando a variabilidade do comportamento hidrometeorológico da área.

O Climograma (Figura 4C) ilustra os dois climas distintos do Clima Tropical, marcado pelas duas estações bem definidas, que confirma a sazonalidade do clima na área. As maiores precipitações ocorreram em janeiro e dezembro com 273,80 e $251,90 \mathrm{~mm}$, respectivamente, e as menores em junho, julho e agosto com 23,40, 21,00 e 21,60 mm, respectivamente (Figura 4C), conforme Aquino et al., (2012), para o sul de Minas Gerais. A Figura 4D apresenta os dados de vazão e precipitação média anual para o período de estudo, que permite avaliar o comportamento da conversão chuva-vazão entre 1994 e 2013.

As precipitações médias mensais de 1994 a 2013 estão ilustradas na Figura 5, que identifica os maiores valores de precipitação associados à Serra da Mantiqueira, na porção sul da bacia. Esse acúmulo de precipitação na região serrana é devido à orografia (MENDELSOHN et al. 2007).

Para fins didáticos, a legenda da Figura 5 deve ser interpretada em função de cada mês separadamente, apontando assim, os locais com maiores precipitações. O uso de uma escala única para todo ano, impediria que fosse possível visualizar diferenças de intensidade de chuva na área de estudo em cada mês.

A análise comparativa das similaridades das informações no conjunto de dados CHIRPS e das 183 estações meteorológicas brasileiras feita por Costa et al., (2019) ratificou coeficiente de determinação de 98\% para a região sudeste do país. Tais autores concluem que entre 1998 e 2010 os dados validados do CHIRPS são confiáveis. Portanto, os dados do CHIRPS podem ser utilizados com confiança para pesquisas climáticas com economia de tempo e recursos, o que valida fortemente o uso de dados de sensoriamento remoto nestes estudos. O período abordado nesta pesquisa praticamente se sobrepõe ao estudado pelos autores e dessa forma pode ser entendido como representativo da área estudada (REBOITA et al. 2010). Além disso, a Figura 5 permite a identificar os locais com as maiores precipitações médias mensais e apontar aquelas sujeitas a regimes pluviométricos mais intensos.

A avaliação dos atributos morfométricos e hidrológicos da bacia indica a necessidade de estabelecer normas de uso e ocupação do solo, a fim de minimizar os prejuízos decorrentes das enchentes e inundações. Dentre elas, é possível propor a necessidade de elaboração de zoneamento para o uso e ocupação da terra em função das características fisiográficas e da vulnerabilidade à eventos catastróficos. É necessário considerar as características morfométricas e hidrológicas, o uso e ocupação das terras e as atividades urbanas e rurais para manter a população das áreas vulneráveis em segurança. É necessário impedir a ocupação das planícies de inundação dos rios, córregos afluentes do Alto Sapucaí para evitar os danos catastróficos das enchentes de dezembro a março (SILVA et al. 2014; SANGMAN \& BALAMURUGAN, 2017). 


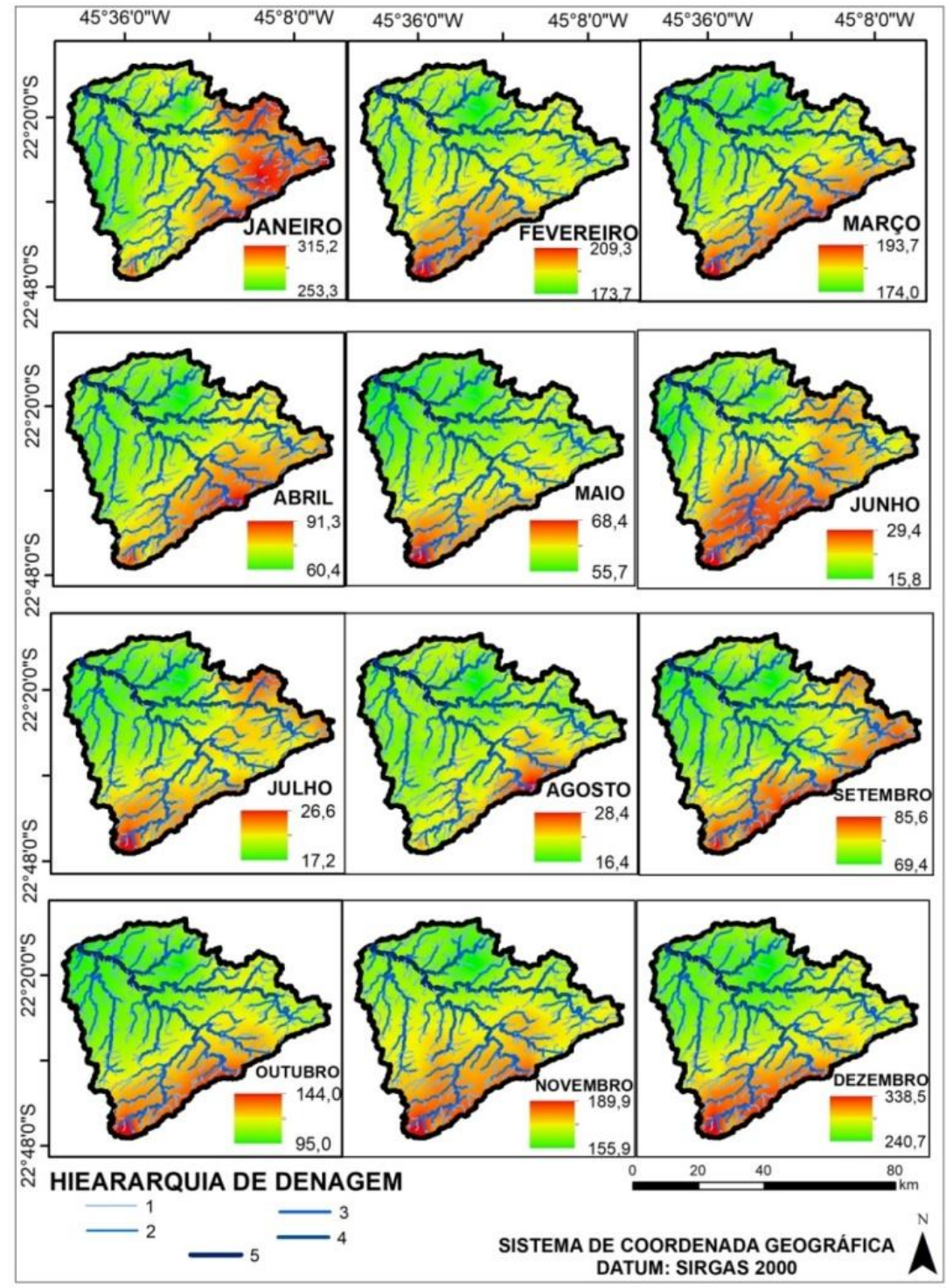

Figura 5: Precipitação média mensal em milímetros da Bacia Hidrográfica do Alto Sapucaí, MG, de 1994 a 2013. Fonte: CHIRPS (2020).

A elaboração de um plano emergencial e de um protocolo para ações anteriores e posteriores aos desastres é fundamental para assegurar o bem-estar da população que ocupa as planícies de inundação da bacia hidrográfica. Entretanto, este protocolo de atuação frente aos desastres requer investimentos. Esse fato, porém, foge da realidade dos municípios brasileiros que muitas vezes negligenciam os investimentos em infraestruturas de combate a enchentes e inundações. Tais protocolos devem ser elaborados por pessoal capacitado com parceria entre o poder público e as entidades privadas. Além disso, devem ter como objetivo principal assegurar o bem-estar da população e das infraestruturas instaladas no interior de áreas de risco a enchentes e inundações (YUNUS et al. 2014; ANGILLIERI \& FERNÁNDEZ, 2017).

O gerenciamento de desastres naturais é um dos instrumentos de planejamento urbano, que, em conjunto com outras políticas públicas podem contribuir para mitigar, prevenir e controlar, de forma permanente, os riscos de desastres naturais. As medidas de prevenção à enchentes e inundações ocorrem antes, durante e após os eventos catastróficos. As medidas que ocorrem antes dos eventos extremos visam de prevenir, mitigar alertar e preparar a sociedade para uma resposta emergencial e imediata ao fenômeno. Sendo assim, passa pela elaboração do mapeamento de riscos, elaboração de sistemas de alerta eficientes e seguros, treinamento e capacitação de recursos humanos e da população vulnerável e obras de engenharia para atender às demandas de escoamento superficial e de infiltração das águas pluviais (KOBIYAMA et al. 2006).

As ações que devem ocorrer durante o evento têm o intuito de garantir uma resposta rápida ao desastre. Assim, estão associadas ao corpo de bombeiros e à defesa civil, que estão capacitados para agir de forma rápida e eficaz protegendo a vida dos atingidos pelas catástrofes (DEFESA CIVIL, 2020). 
Por fim, as ações que ocorrem posteriores aos desastres remetem a reabilitação e reconstrução das áreas atingidas, buscando minimizar os prejuízos, investimentos em pesquisas e o desenvolvimento e expansão dos sistemas de monitoramento e alerta de desastres.

Entretanto, estas medidas não resolvem completamente o problema (DUZI et al. 2017). Uma solução efetiva passa pelo processo de zoneamento e reformas urbanas que dependem de planejamento, pessoal técnico capacitado e decisão política. Vale salientar que o interesse da coletividade deve prevalecer sobre os interesses políticos e econômicos (DUZI et al. 2017; VAN BERCHUM, 2019).

A estratégia apresentada é eficaz, pois além de garantir a qualidade e disponibilidade de água para abastecimento público, também controla a vazão e a captação de águas da chuva favorecendo a infiltração e assegurando a prestação de serviços ambientais e ecossistêmicos. Incentiva também a prática de atividades ao ar livre com consolidação de áreas verdes de uso comunitário (KOBIYAMA et al. 2006; SERVIDONI et al. 2019; YAN et al. 2019).

A relação entre espaço e Estado deve ser percebida e abordada no gerenciamento de risco, pois os fenômenos ocorrem devido à configuração dos elementos urbanos que são produtos do avanço da acumulação capitalista. Esse acúmulo se sobrepõe aos interesses da coletividade e promovem a formação de aglomerados com menor infraestrutura, geralmente em áreas periféricas. Tais áreas comumente são as mais atingidas por catástrofes naturais, pois estão sobrepostas a áreas vulneráveis dotadas de menor infraestrutura onde o interesse estatal é menor, pois não representam o berço das relações capitalistas nas cidades (ARAÚJO, 2020)

Este estudo permitiu identificar fragilidades e potencialidades da rede hidrográfica e do relevo visando auxiliar o planejamento do uso e ocupação do solo e a proteção da vida, especialmente a humana. Além da redução dos prejuízos financeiros relacionados à infraestrutura urbana causados pelas enchentes e inundações na Bacia Hidrográfica do Alto Sapucaí. Visa também contribuir com o debate cientifico sobre os impactos das mudanças climáticas e o aumento de eventos extremos, como os observados de forma recorrente durante a estação chuvosa (FONSECA \& AUGUSTIN, 2014; GAJBHIYE, 2015).

\section{Conclusões}

A análise permite avaliar a distribuição espaço-temporal do comportamento hidrometeorológico em bacias hidrográficas e permite colaborar com o planejamento da gestão de áreas de risco.

As características geomorfológicas dos rios, devido ao relevo e à geologia contribuem para ampliar a vazão nos eventos de precipitação.

Os valores obtidos para densidade de drenagem, densidade de rios e coeficiente de compacidade indicam que a área é propensa a enchentes e inundações.

A sazonalidade do clima deve ser considerada no planejamento das políticas de uso e ocupação das terras, pois promove, em regiões tropicais, a alternância de estações chuvosas e secas, o que interfere diretamente no planejamento do uso do solo e ações de prevenção às enchentes e inundações.

\section{Referências}

ALMEIDA, R. A.; ROSA, D. R. Q.; FERREIRA, R. G.; DELAZARI, F. T.; ALMEIDA, I. A. Análise morfométrica de uma sub-bacia do rio Piracicaba (MG) utilizando sistemas de informação geográfica. Revista Engenharia na Agricultura, Viçosa, v. 25, p. 372-380, 2017. https://doi.org/10.13083/reveng.v25i4.815

ALMEIDA, W. S.; SOUZA, N. M.; JUNIOR, D. S. R.; CARVALHO, J. C. Análise morfométrica em bacias hidrográficas fluviais como indicadores de processos erosivos e aportes de sedimentos no entorno do reservatório da usina hidrelétrica (UHE) corumbá IV. Revista Brasileira de Geomorfologia, Brasília, v. 14, p. 135-140, 2013. https://doi.org/10.20502/rbg.v14i2.

ANGILLIERI, M. Y. E.; FERNÁNDEZ, O. M. Morphometric analysis of river basins using GIS and remote sensing of an Andean section of Route 150, Argentina. A comparison between manual and automated delineation basins. Revista Mexicana de Ciências Geológicas, Cidade do México, v. 34, p. 150-156, 2017. https://doi.org/10.22201/cgeo. 20072902e.2017.2.482. 
AQUINO, R. F.; SILVA, M. L N.; DE FREITAS, D. A. F.; CURI, N.; MELlO, C. R.; AVANZI, J. C. Spatial variability of the rainfall erosivity in southern region of Minas Gerais State, Brazil. Ciência e Agrotecnologia, Lavras, v. 36, p. 533-542, 2012. https://doi.org/10.1590/S1413-70542012000500006.

ARAÚJO, J. A. Aplicação de elementos da teoria das catástrofes ao estudo da (re) produção do espaço urbano: parte 1 - como Henri Lefebvre trouxe René Thom para o debate. Revista do Departamento de Geografia, São Paulo, v. 39, p. 14-24, 2020. https://doi.org/10.11606/rdg.v39i0.157576

BRASIL. Política Nacional de Recursos Hídricos. Lei no 9.433, de 8 de Janeiro de 1997. Disponível em: http://www.planalto.gov.br/ccivil_03/leis/19433.htm.

COSTA, J.; PEREIRA, G.; SIQUEIRA, M. E.; CARDOZO, F.; SILVA, V. V. Validação dos dados de precipitação estimados pelo CHIRPS para o Brasil. Revista Brasileira de Climatologia, Curitiba, v. 24, p. 228-243, 2019. https://doi.org/10.5380/abclima.v24i0.60237.

CPRM - SERVIÇO GEOLÓGICO DO BRASIL. Carta Geológica Guaratinguetá, Escala 1:250.000, 1998. Disponível em: http://geosgb.cprm.gov.br/geosgb/downloads.html

CELARINO, A. L. S.; LADEIRA, F. S. B. Análise morfométrica da bacia do Rio Pardo. Revista Brasileira de Geomorfologia, Brasília, v. 15, p. 471-491, 2014. https://doi.org/10.20502/rbg.v15i3.

CHIRPS - CLIMATE HAZARD CENTER. Rainfall Estimates from Rain Gauge and Satellite Observations. 2020. Disponível em: www.chc.ucsb.edu/data/chirps.

CHRISTOFOLETTI, A. A análise morfométrica de bacias hidrográficas. Notícias Geomorfológicas, Rio Claro, v. 18, p. 35-64, 1969.

DEFESA CÍVIL. Boletim Estadual de Proteção e Defesa Civil. 2020. Disponível em: http://www.defesacivil.mg.gov.br.

DUZI, B.; VIKHROV, D.; KELMAN, I.; STOJANOV, R.; JURICKA. Household measures for river flood risk reduction in the Czech Republic. Journal of Flood Risk Management, Londres, v. 12, p. 253-266, 2017. https://doi.org/10.1111/jfr3.12132

ESRI - ENVIRONMENTAL SYSTEMS RESEARCH INSTITUTE. ARCGIS professional GIS for the desktop version 10.3. 2015 Manual do usuário. Disponível em: https://esripress.esri.com/bookResources/index.cfm?event=catalog.index

FONSECA, B. M.; AUGUSTIN, C. H. R. R. Análise Morfométrica de bacias de drenagem e sua relação com a estrutura geológica na serra do espinhaço meridional - MG. Revista Brasileira de Geomorfologia, Brasília, v. 15, p. 153-172, 2014. https://doi.org/10.20502/rbg.v15i2.296.

GAILLETON, B.; MUDD, S.M.; CLUB, F. J.; PEIFER, D.; HURST, M. D. A segmentation approach for the reproducible extraction and quantification of knickpoints from river long profiles. Earth Surface Dynamics, Strasbourg, v. 7, p. 211-230, 2019. https://doi.org/10.5194/esurf-7-211-2019

GAJBHIYE, S. Morphometric Analysis of a Shakkar River Catchment Using RS and GIS. International Journal of u-and e- Service, Science and Technology, Stanford, v. 8, p. 11-24, 2015. https://doi.org/10.14257/ijunesst.2015.8.2.02.

GUPTA, D. S.; GOSH, P.; TRIPATHI, S. K. A Quantitative Morphometric Analysis of Barhar River Watershed of Mahoba district, U.P., India using Remote Sensing and GIS. Indian Jounal of Science and Technology, Bagarole, v. 10, p. 1-5, 2017. https://doi.org/10.17485/ijst/2017/v10i11/109695.

HORTON, R. E. Erosional development of streams and their drainage basins: hydrophysical approach to quantitative morphology. Geological Society of America Bulletin, Boulder, v. 56, p. 275-370, 1945. https://doi.org/10.1130/0016-7606(1945)56[275:EDOSAT]2.0.CO;2 
KOBIYAMA, M.; MENDONÇA, M.; MORENO D. A; MARCELINO, I. P. V. O; MARCELINO, E. V.; GONÇALVES, E. F.; BRAZELETTI, L. L. P.; GOERL, R. F.; MOLLERI, G.; RUDORFF, F. Prevenção de desastres naturais: conceitos básicos. Curitiba: Organic Trading, 2006, 109p.

KUNTAMALLA, S.; NALLA, M.; SAXENA, P.R. Drainage Basin Analysis through GIS: A Case study of Lakhnapur Reservoir Watershed in Rangareddy District, Telangana State, India. International Journal of Engineering, Science and Mathematics, Jahadhri, v. 7, p. 9-17, 2018. https://doi.org/10.13140/RG.2.2.22464.84484

MEDHI, B.; CHAKRAVARTTY, M.; PATGIRI, A. D. Infering Hydrological Characteristics of Gabharu River Basin, North-East India, Based on the Application of Some Important Morphometric Parameters. Global Journal for Research Analysis, Gujarate, v. 6, p. 10-12, 2017. https://doi.org/10.36106/gira

MELlO, C. R.; SÁ, M. A. C.; CURI, N.; MELLO, J. M.; VIOLA, M. R.; SILVA, A. M Erosividade mensal e anual no Estado de Minas Gerais. Pesquisa Agropecuária Brasileira, Brasília, v. 42, p. 537-545, 2007. https://doi.org/10.1590/S0100-204X2007000400012.

MENDELSOHN, R.; KURUKULASURIYA, P.; BASIST, A.; KOGAN, F.; WILLIAMS, C. Climate analysis with satellite versus weather station data. Climatic Change, Basingstoke, v. 81, p. 71-83, 2007. https://doi.org/10.1007/s10584-006-9139-x.

NAGARAJU, S. K.; BHANUPRAKASH, D.; SHIVASWAMY, H. M.; BALASUBRAMANIAN, A. Morphometric Evaluation and Sub Basin Analysis in Hanur Watershed, Kollegal Taluk, Chamarajanagar District, Karnataka, India, using Remote Sensing and GIS Techniques. International Journal of Advanced Remote Sensing and GIS, Gujarat, v. 6, p. 2178-2191, 2017. https://doi.org/10.23953/cloud.ijarsg.265.

PUROHIT, K.; PARMAR, M. K. Morphometric Analysis and Correlation between Morphometric Parameters with Mean Basin Altitude and Slope: A case study of Alaknanda Basin, Uttarakhand, India. Global Journal for Research Analysis, Ahmedabad, v. 6, p. 27-30, 2017.

https://doi.org/10.36106/gira.

REBOITA, M. S.; GAN, M. A.; ROCHA, R. P. da; AMBRIZZI, T. Regimes de precipitação na América do Sul: uma revisão bibliográfica. Revista Brasileira de Meteorologia, São José dos Campos, v. 25, p. 185-204, 2010. https://doi.org/10.1590/S0102-77862010000200004.

RIBEIRO, A. S.; MINCATO, R. L.; CURI, N.; KAWAKUBO, F. S. Vulnerabilidade ambiental à erosão hídrica em uma sub-bacia hidrográfica pelo processo analítico hierárquico. Revista Brasileira de Geografia Física, Recife, v. 9, p. 16-31, 2016. https://doi.org/10.26848/rbgf.v9.1.p016-031.

SANGMAN, F.; BALAMURUGAN, G. Morphometric Analysis of Kakoi River Watershed for Study of Neotectonic Activity Using Geospatial Technology. International Journal of Geoscience, Paris, v. 8, p. 1384-1403, 2017. https://doi.org/10.4236/ijg.2017.811081.

SCOLFORO, J. R. S.; MELLO, J. M.; SILVA, C.P.C. Inventário Florestal de Minas Gerais: Floresta Estacional Semidecidual e Ombrófila - Florística, Estrutura, Diversidade, Similaridade, Distribuição diamétrica e de altura, Volumetria e Tendências de crescimento e Áreas aptas para manejo florestal. Lavras: UFLA, 2008, 1029p.

SCHUMM, S. A. Evolution of drainage systems and slopes in badlands at Perth Amboy, New Jersey. Geological Society of America Bulletin, Tysons, v. 67, p. 597-646, 1956. https://doi.org/10.1130/00167606(1956)67[597:EODSAS]2.0.CO;2

SERVIDONI, L. E.; TEODORO, A. E. M.; MINCATO, R. L.; SANTOS, C. A. Avaliação de risco a enchentes e inundações por krigagem ordinária em sistemas de informação geográfica. Revista Caderno de Geografia, Belo Horizonte, v. 29, p. 126-143, 2019. https://doi.org/10.5752/p.2318-2962.2019v29nespp126.

SGARBI, G. N. C.; DARDENNE, M. A. Evolução climática do Gondwana nas regiões centro-sul do Brasil e seus registros geológicos continentais durante o Mesozóico, enfatizando o ardo do Alto Paranaíba, a borda 
NNE da Bacia do Paraná e a Porção meridional da bacia sanfranciscana no oeste do estado de Minas Gerais.

Geonomos, Belo Horizonte, v. 4, p. 21-49, 2002. https://doi.org/10.18285/geonomos.v4i1.193

SILVA, M.T.; SILVA, V. P. R.; SOUZA, E. P.; OLIVEIRA, V. G. Morphometric Analysis of the Basin Low Middle São Francisco River. Journal of Hyperspectral Remote Sensing, Recife, v. 4, p. 168-174, 2014. https://doi.org/10.29150/jhrs.v4.8.p168-174.

STRAHLER, A. N. Hypsometric (area-altitude) analysis of erosional topography. Geological Society of America Bulletin, Washington v. 63, p. 1117-1142, 1952. DOI: https://doi.org/10.1130/00167606(1952)63[1117:HAAOET]2.0.CO;2

STRAHLER, A. N. Quantitative analysis of watershed geomorphology. Transactions, American Geophysical Union, Washington, v. 38, p. 913-920, 1957. https://doi.org/10.1029/TR038i006p00913

SPAROVEK, G.; VAN LIER, Q. J.; NETO, D. Computer assisted Köppen climate classification: case study for Brazil. International Journal Climatology, Amsterdam, v. 27, p. 257-266, 2007. https://doi.org/10.1002/joc.1384.

TAOFIK, O. K.; INNOCENT, B.; CHRISTOPHER, N.; JIDAUNA, G. G.; JAMES, A. S. A Comparative Analysis of Drainage Morphometry on Hydrologic Characteristics of Kereke and Ukoghor Basins on Flood Vulnerability in Makurdi Town, Nigeria. Hydrology, Amsterdam, v. 5, p. 32-40, 2017.

https://doi.org/10.11648/j.hyd.20170503.11.

ULIBARRI, N.; GARCIA, N. E. Comparing Complexity in Watershed Governance: The Case of California. Water, Basel, v.12, p. 766-785, 2020. https://doi.org/10.3390/w12030766.

VIANNA, M. P.; AVELAR, W. E. O. Ocorrência da espécie invasora Corbicula flumínea (Bivalvia, Corbiculidae) no Rio Sapucaí (São Paulo, Brasil). Biotemas, Florianópolis, v. 23, p. 56-66, 2010.

https://doi.org/10.5007/2175-7925.2010v23n3p59.

VAN BERCHUM, E. C.; MOBLEY, W.; JONKMAN, S. N.; TIMMERMANS, J. S.; KWAKKEL, J. H.; BRODY S.D. Evalution of flood risk reduction strategies through combinations of interventions. Jounal of Flood RIsk Management, Londres, v. 12, p. 1-17, 2019. https://doi.org/10.1111/jfr3.12506

YUNUS, A. P.; OGUCHI, T.; HAYAKAWA, Y. S. Morphometric Analysis of Drainage Basins in the Western Arabian Peninsula Using Multivariate Statistics. International Journal of Geosciences, Paris, v. 5, p. 527-539, 2014. https://doi.org/10.4236/ijg.2014.55049.

YAN, L.; XIONG, L.; RUAN, G.; XU C.; YAN, P.; LIU, P. Reducing uncertainty of design floods of twocomponent mixture distributions by utilizing flood timescale to classify flood types in seasonally snow covered region. Journal of Hydrology, Amsterdam, v. 574, p. 588-608, 2019. https://doi.org/10.1016/j.jhydrol.2019.04.056.

WU, H.; KIMBALL, J. S.; ZHOU, N.; ALFIERI, L.; LUO, L.; DU, J.; HUANG, Z. Evaluation of real-time global flood modeling with satellite surface inundation observations from SMAP. Remote Sensing of Environment, Amsterdam, v. 233, p. 1-15, 2019. https://doi.org/10.1016/j.rse.2019.111360.

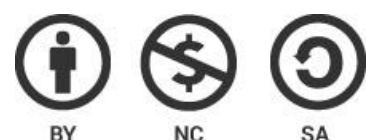

Este artigo é distribuído nos termos e condições do Creative Commons Attributions/AtribuiçãoNãoComercial-CompartilhaIgual (CC BY-NC-SA). 